\title{
Long-term endocrine outcome of suprasellar arachnoid cysts
}

\author{
Ji Yeoun Lee, MD, PhD, ${ }^{1,2}$ Young Ah Lee, MD, PhD, ${ }^{3}$ Hae Woon Jung, MD, ${ }^{3}$ Sangjoon Chong, MD, ${ }^{2}$ \\ Ji Hoon Phi, MD, PhD, ${ }^{2}$ Seung-Ki Kim, MD, PhD, ${ }^{2}$ Choong-Ho Shin, MD, PhD, ${ }^{3}$ and \\ Kyu-Chang Wang, MD, PhD²
}

\begin{abstract}
'Department of Anatomy and Cell Biology, Seoul National University College of Medicine; and 2Division of Pediatric Neurosurgery, ${ }^{3}$ Department of Pediatrics, Seoul National University Children's Hospital, Seoul National University College of Medicine, Seoul, Korea
\end{abstract}

\begin{abstract}
OBJECTIVE Due to their distinct location, suprasellar arachnoid cysts are known to cause a wide variety of problems, such as hydrocephalus, endocrine symptoms, and visual abnormalities. The long-term outcome of these cysts has not been elucidated. To find out the long-term outcome of suprasellar arachnoid cysts, a retrospective review of the patients was performed. The neurological and endocrine symptoms were thoroughly reviewed.

METHODS Forty-five patients with suprasellar arachnoid cysts, with an average follow-up duration of 9.7 years, were enrolled in the study. A comprehensive review was performed of the results of follow-up regarding not only neurological symptoms but also endocrine status. The outcomes of 8 patients who did not undergo operations and were asymptomatic or had symptoms unrelated to the cyst were included in the series.
\end{abstract}

RESULTS Surgery was most effective for the symptoms related to hydrocephalus (improvement in 32 of 32), but endocrine symptoms persisted after surgery (4 of 4) and required further medical management. More surprisingly, a fairly large number of patients (14 of 40; 1 was excluded because no pre- or postoperative endocrine evaluation was available) who had not shown endocrine symptoms at the time of the initial diagnosis and treatment later developed endocrine abnormalities such as precocious puberty and growth hormone deficiency. The patients with endocrine symptoms detected during the follow-up included those in both the operated $(n=12$ of 32) and nonoperated $(n=2$ of 8$)$ groups who had been stable during follow-up since the initial diagnosis.

CONCLUSIONS This study implies that patients with suprasellar arachnoid cysts can develop late endocrine problems during follow-up, even if other symptoms related to the cyst have been successfully treated. Hence, patients with these cysts need long-term follow-up for not only neurological symptoms but also endocrine abnormalities.

https://thejns.org/doi/abs/10.3171/2017.1.PEDS16404

KEY WORDS arachnoid cyst; suprasellar; endocrine outcome; hormone; congenital

$\mathrm{S}$ UPRASELLAR arachnoid cysts constitute 5\%-12\% of intracranial arachnoid cysts. ${ }^{11}$ They are known to be associated with hydrocephalus and to cause visual and endocrine dysfunction due to their anatomical locations. ${ }^{2,7}$ The most controversial topic on suprasellar cysts has been the optimal choice of surgical modality. First, operations using only fenestration precluded shunt procedures including ventriculoperitoneal shunting (VPS) and cystoperitoneal shunting (CPS) as the surgical modality of treatment. ${ }^{6}$ Later a controversy developed between micro- scopic and endoscopic fenestration; since then, a general consensus has been reached that endoscopic fenestration is preferred when feasible. ${ }^{10}$ The most recent issue is whether ventriculocystostomy or ventriculocystocisternostomy should be performed. ${ }^{8,13,16,19}$ Numerous reports have addressed this issue, and it appears to be an ongoing debate.

Despite the detailed discussion regarding surgical modalities, the long-term outcomes of suprasellar arachnoid cysts have not been thoroughly elucidated. Through a retrospective review of a relatively large number of patients

ABBREVIATIONS ACTH = adrenocorticotropic hormone; CPS = cystoperitoneal shunting; GH = growth hormone; GnRH = gonadotropin-releasing hormone; VPS = ventriculoperitoneal shunting.

SUBMITTED July 13, 2016. ACCEPTED January 11, 2017.

INCLUDE WHEN CITING Published online March 24, 2017; DOI: 10.3171/2017.1.PEDS16404. 
TABLE 1. Demographics and clinical features of patients in the study

\begin{tabular}{lc}
\hline \multicolumn{1}{c}{ Clinical Features $(\mathrm{n}=45)$} & Value (range) \\
\hline $\mathrm{M} / \mathrm{F}$ & $24 / 21$ \\
\hline Mean age at initial operation in yrs & $2.8(0.5-18.0)$ \\
\hline Mean follow-up duration in yrs & $9.7(0.1-20.9)$ \\
\hline Mean age at last follow-up in yrs & $14.0(1.6-27.4)$ \\
\hline Treatment & 37 \\
\hline Operation & 6 \\
\hline Microscopic fenestration & 9 \\
\hline Shunting (CPS or VPS) \pm fenestration & 22 \\
\hline Endoscopic fenestration & 8 \\
\hline No operation & 32 \\
\hline Hydrocephalus & 13 \\
\hline Reoperation & \\
\hline
\end{tabular}

with suprasellar arachnoid cysts and long follow-up durations, this study uncovered new aspects of this disease that are particularly related to endocrine outcomes. The longterm outcomes of patients who have not been treated with surgery are also described.

\section{Methods \\ Data Collection}

We searched the electronic medical records of the patients who visited the outpatient clinic of Seoul National University Children's Hospital between 2000 and 2014. The patients with either the registered diagnosis of "suprasellar arachnoid cyst," "arachnoid cyst," or those with the words "suprasellar cyst" on the radiology report of brain imaging (using a free-text search) were listed. The brain imaging of all patients was reviewed manually to select those with arachnoid cysts located in the suprasellar location. A retrospective review of the medical records was performed for the demographic data, operational procedures, and symptomatic changes during follow-up. As the operational procedure, CPS or VPS was used during the early period, but since the 2000 s, fenestration procedures became the primary choice, and endoscopic fenestration gradually became the method used most often. Currently, endoscopic fenestration is the treatment of choice for suprasellar arachnoid cysts, and ventriculocystocisternostomy is performed if possible. The indication for surgery varied between surgeons. The only absolute indication for surgical intervention was hydrocephalus. Incidental, asymptomatic lesions without hydrocephalus were not operated on and were observed in the outpatient clinic. Imaging follow-up was performed for all patients. Ophthalmological evaluation was conducted in symptomatic patients. Postoperative endocrine evaluation was also not performed routinely, but recently we have changed our strategy to allow patients to undergo regular evaluation by pediatric endocrinologists.

\section{Statistical Analysis}

For statistical analysis, the Fisher's exact test and Mann-Whitney U-test were used accordingly. This study
TABLE 2. Preoperative clinical manifestation of suprasellar arachnoid cysts

\begin{tabular}{lc}
\hline \multicolumn{1}{c}{ Symptom } & No. of Patients \\
\hline Motor development delay & 8 \\
\hline Fetal diagnosis & 8 \\
\hline Incidental & 6 \\
\hline Headache & 6 \\
\hline Nausea/vomiting & 6 \\
\hline Seizure & 3 \\
\hline Strabismus/EOM limitation & 4 \\
\hline Large head & 3 \\
\hline Decrease of visual acuity & 2 \\
\hline Endocrine disorders (3 PP, $1 \mathrm{HH})$ & 4 \\
\hline Head bobbing & 1 \\
\hline Lethargy & 1 \\
\hline Staring & 1 \\
\hline
\end{tabular}

EOM = extraocular movement (caused specifically by cranial nerve dysfunction); $\mathrm{HH}$ = hypogonadotropic hypogonadism; $\mathrm{PP}$ = precocious puberty.

was approved by the Institutional Review Board of Seoul National University Hospital.

\section{Results}

\section{Initial Presentation and Surgical Indication}

A total of 45 patients ( 24 boys and 21 girls) were included in this study (Table 1). The median age at the initial operation or visit was 2.8 years (range $0.5-18.0$ years) with a mean follow-up duration of 9.7 years. Thirty-seven of the patients underwent operations, and 8 were not treated surgically. Twenty-two patients were treated with endoscopic fenestration, 6 with microscopic fenestration, and 9 received shunt insertions with $(n=4)$ or without $(n=5)$ fenestration as the initial operation.

Of the 45 patients, 6 (13\%) were diagnosed incidentally (Table 2). The most common symptom at diagnosis was motor developmental delay $(\mathrm{n}=8,18 \%)$. In this series, hydrocephalus was detected in all patients who presented with motor developmental delay. Equal numbers of patients were diagnosed during fetal screening $(\mathrm{n}=8)$. Endocrine abnormalities at diagnosis were found in 4 patients (9\%). Two patients presented with decreased visual acuity. Head bobbing was noted in 1 patient. Some patients had more than 1 symptom at presentation.

All patients with hydrocephalus $(n=32)$ underwent operations. Hydrocephalus was defined as ventriculomegaly with signs of increased intracranial pressure such as headache, nausea, vomiting, papilledema, bulged fontanelle, etc. The surgical indications for the 5 patients without hydrocephalus included chronic, nonprojectile vomiting $(\mathrm{n}=$ 1, age 6.1 years), nonspecific staring not related to seizure ( $\mathrm{n}=1$, age 1.1 years), strabismus $(\mathrm{n}=1$, age 5.6 years), and enlargement of the cyst $(n=2$, ages 0.8 and 2.5 years; volume enlargement by 10.1 -fold and 5.6-fold). Vomiting and nonspecific staring which were transient or not supported by neuroimaging studies were regarded as unrelated to the cyst. 
TABLE 3. Details of patients with endocrine dysfunction

\begin{tabular}{|c|c|c|c|c|c|c|c|c|c|c|c|}
\hline \multirow[b]{2}{*}{ Case No. } & \multirow[b]{2}{*}{ Sex } & \multicolumn{3}{|c|}{ Age (yrs) } & \multicolumn{3}{|c|}{$\begin{array}{c}\text { Age at Diagnosis of } \\
\text { Endocrine Problem (yrs) }\end{array}$} & \multirow[b]{2}{*}{$\begin{array}{c}\text { Age at } \\
\text { Last FU } \\
\text { (yrs) }\end{array}$} & \multirow[b]{2}{*}{$\mathrm{HC}$} & \multirow[b]{2}{*}{ Type of Op } & \multirow[b]{2}{*}{ Treatment } \\
\hline & & $\begin{array}{c}\text { At Diagnosis } \\
\text { of SSAC }\end{array}$ & $\begin{array}{l}\text { At } \\
\text { Op }\end{array}$ & $\begin{array}{l}\text { At Diagnosis of } \\
\text { 1st Endocrine } \\
\text { Problem }\end{array}$ & PP & $\begin{array}{c}\mathrm{GH} \\
\text { Deficiency }\end{array}$ & HYG & & & & \\
\hline \multicolumn{12}{|l|}{ Initially } \\
\hline 5 & $\mathrm{~F}$ & 8.8 & 8.8 & 8.8 & 8.8 & - & - & 13.0 & Yes & CPS & None \\
\hline 1 & M & 9.7 & 9.7 & 9.7 & 9.7 & - & NA & 19.4 & Yes & $\mathrm{EF}$ & GnRH analog \\
\hline 43 & M & 8.4 & 8.5 & 8.4 & 8.4 & - & NA & 9.5 & Yes & MF, CPS & GnRH analog \\
\hline 3 & $\mathrm{~F}$ & 17.9 & 18.0 & 15.0 & - & 15.0 & 15.0 & 25.2 & Yes & EF, VPS & $\mathrm{GH}$, sex hormone \\
\hline \multicolumn{12}{|l|}{ During FU } \\
\hline 16 & $\mathrm{~F}$ & 2.1 & 2.1 & 6.8 & 6.8 & 8.6 & - & 19.8 & Yes & $\mathrm{MF}+\mathrm{CPS}, \mathrm{EF}$ & $\mathrm{GH}, \mathrm{GnRH}$ analog \\
\hline $34^{*}$ & $\mathrm{~F}$ & 2.1 & 2.2 & 2.9 & 5.7 & 2.9 & NA & 10.8 & Yes & $\mathrm{EF}$ & $\mathrm{GH}, \mathrm{HCS}, \mathrm{GnRH}$ analog \\
\hline 8 & $\mathrm{~F}$ & 1.1 & 1.1 & 5.5 & - & 5.5 & 15 & 22.0 & Yes & VPS & $\mathrm{GH}$, sex hormone \\
\hline 33 & M & 5.5 & - & 9.8 & 9.8 & - & - & 15.7 & No & & GnRH analog \\
\hline 36 & $\mathrm{~F}$ & 1.5 & 1.5 & 5.9 & 5.9 & - & NA & 9.3 & Yes & EF & GnRH analog \\
\hline 7 & $\mathrm{~F}$ & 1.7 & 1.8 & 8.3 & 8.3 & - & - & 21.1 & Yes & MF, CPS, CPS & GnRH analog \\
\hline 37 & $\mathrm{~F}$ & 5.9 & 6.0 & 7.4 & 7.4 & - & NA & 9.5 & Yes & $\mathrm{EF}$ & GnRH analog \\
\hline $15 \dagger$ & M & 1.0 & 1.2 & 10.7 & 10.7 & - & - & 17.3 & Yes & EF, VPS, VPS & None \\
\hline 23 & $\mathrm{~F}$ & 2.0 & 2.0 & 7.0 & 7.0 & - & - & 15.3 & Yes & $\mathrm{EF}$ & GnRH analog \\
\hline 28 & $\mathrm{~F}$ & Prenatal & - & 8.3 & 8.3 & - & NA & 11.4 & No & & GnRH analog \\
\hline 4 & M & 2.1 & 2.1 & 9.8 & 9.8 & - & - & 19.2 & Yes & MF, CPS, VPS & GnRH analog \\
\hline 21 & M & 7.4 & 7.5 & 15.1 & - & 15.1 & 15.1 & 21.8 & Yes & $\mathrm{EF}$ & GH, sex hormone \\
\hline 18 & M & 5.6 & 5.6 & 9.7 & 9.7 & - & - & 19.8 & Yes & $\mathrm{EF}$ & None \\
\hline 41 & $\mathrm{~F}$ & Prenatal & 0.8 & 4.0 & 4.0 & - & NA & 4.6 & No & MF, CPS & GnRH analog \\
\hline
\end{tabular}

$\mathrm{EF}=$ endoscopic fenestration; $\mathrm{FU}$ = follow-up; $\mathrm{HC}$ = hydrocephalus; $\mathrm{HCS}$ = hydrocortisone; $\mathrm{HYG}=$ hypogonadism; $\mathrm{MF}=$ microscopic fenestration; $\mathrm{NA}=$ not available; SSAC $=$ suprasellar arachnoid cyst.

* Only case with ACTH deficiency, diagnosed at 2.9 years of age.

$\dagger$ Only case with hypothyroidism, diagnosed at 10.7 years of age.

The 8 cases that were not operated on were incidental $(\mathrm{n}=3$; ages $2.7,5.5$, and 6.8 years; follow-up durations $3.8,9.2$, and 11.9 years), asymptomatic after fetal diagnosis $(\mathrm{n}=4$, all at birth; follow-up durations 1.6, 3.2, 10.0, and 11.4 years), or had nonspecific nausea and vomiting that resolved spontaneously ( $\mathrm{n}=1$, age 9.5 years, followup duration 0.5 years).

\section{Surgical Outcomes}

The symptoms caused by increased intracranial pressure related to hydrocephalus, such as headache, nausea, and vomiting, improved in all patients. Motor development delay (8 cases) was markedly improved after the resolution of hydrocephalus. Limitations of extraocular movement were resolved after the operations, and complete improvement was also observed in the patient with head bobbing. However, the endocrine symptoms were not improved, and decreased visual acuity and strabismus also persisted after the operations. The symptoms unrelated to the cyst (i.e., headache, seizure, and vomiting with no clear associations with hydrocephalus) did not exhibit definitive clinical improvements.

An acute complication was experienced in 1 patient as a transient limitation in extraocular movement after endoscopic fenestration. The chronic complications con- sisted of shunt-related problems, including shunt malfunction $(n=4)$, shunt infection $(n=4)$, and shunt overdrainage $(n=1)$.

Radiologically, the decreases in cyst sizes and the resolutions of hydrocephalus were confirmed in all cases. The decreases in the sizes of the cysts or ventricles were typically more obvious and prominent in patients with shunt insertions compared with those who received only fenestrations.

\section{Endocrine Outcomes}

Eighteen (41\%) of the 44 patients in whom endocrine data were available exhibited associated endocrine dysfunction (Table 3). For 1 patient, the pre- and postoperative endocrine evaluations were not available and thus were not considered. Four patients ( 3 cases of precocious puberty and 1 case of amenorrhea) were discovered to have endocrine problems at the time of or prior to the diagnosis of the suprasellar arachnoid cysts. None of the 4 patients with preoperative endocrine problems exhibited an alleviation of their endocrine abnormalities postoperatively. Among the 40 patients who were confirmed to be free of endocrine problems at the time of the initial diagnosis, 14 exhibited endocrine disorders during followup. Endocrine disorders, including precocious puberty, 
TABLE 4. Comparison of clinical features according to endocrine results

\begin{tabular}{|c|c|c|c|c|c|c|}
\hline \multirow[b]{2}{*}{$\begin{array}{l}\text { Endocrine } \\
\text { Disorders }\end{array}$} & \multicolumn{2}{|c|}{ Op } & \multicolumn{2}{|c|}{ Hydrocephalus } & \multicolumn{2}{|c|}{ Mean Age (yrs) } \\
\hline & No & Yes & No & Yes & $\begin{array}{c}\text { At Initial } \\
\text { Diagnosis }\end{array}$ & $\begin{array}{c}\text { At Last } \\
\text { FU }\end{array}$ \\
\hline $\begin{array}{l}\text { At initial diagno- } \\
\text { sis }(n=4)\end{array}$ & 0 & 4 & 0 & 4 & 11.3 & 16.8 \\
\hline $\begin{array}{l}\text { Develop during } \\
\quad F U(n=14)\end{array}$ & 2 & 12 & 3 & 11 & 2.8 & 15.5 \\
\hline $\begin{array}{l}\text { None at last FU } \\
\quad(n=26)\end{array}$ & 6 & 20 & 10 & 16 & 4.0 & 12.9 \\
\hline
\end{tabular}

$n=44$, excluding 1 patient without endocrine evaluation.

growth hormone $(\mathrm{GH})$ deficiency, hypogonadotropic hypogonadism, adrenocorticotropic hormone (ACTH) deficiency, and hypothyroidism were newly detected, years after the initial diagnosis of suprasellar arachnoid cysts in both the operated (12 of 32) and nonoperated (2 of 8) patients (Table 3 ). Precocious puberty and GH deficiency were the most common problems.

The clinical features of the patients according to endocrine outcome were compared using Fisher's exact test (Table 4). No significant associations were found between hydrocephalus or the surgical treatment and endocrine outcome. The 4 patients with initial endocrine problems were older at diagnosis than the 14 patients who presented with endocrine disorders later during follow-up and also older than the 26 patients who did not develop endocrine disorders (Mann-Whitney U-test, $\mathrm{p}<0.05$ for later diagnosis or no endocrine disorder group vs initial diagnosis group; Table 4).

\section{Illustrative Cases}

A 2-year-old girl (Case 23) presented with a delay in motor development and was diagnosed with a suprasellar arachnoid cyst with hydrocephalus. She was treated with endoscopic fenestration, and her developmental status improved. She was undergoing routine follow-up evaluation with no active problems when precocious puberty was detected at the age of 7. She was treated with a gonadotropinreleasing hormone $(\mathrm{GnRH})$ analog (Fig. 1). This patient demonstrates a case with later development of endocrine problems after successful surgery.

An 11-day-old girl (Case 28) visited the outpatient clinic for evaluation of a suprasellar arachnoid cyst that was diagnosed during the fetal period. No hydrocephalus was found, so she continued with close follow-up evaluation and remained asymptomatic with spontaneously decreased cyst size. However, precocious puberty was diagnosed at the age of 8 years and treated with a GnRH analog. No changes regarding the arachnoid cyst were detected at the diagnosis of precocious puberty (Fig. 2). This is an example of a patient who developed an endocrine disorder who had not required treatment for the initially asymptomatic suprasellar arachnoid cyst.

\section{Discussion}

This study reviewed the long-term follow-up results of
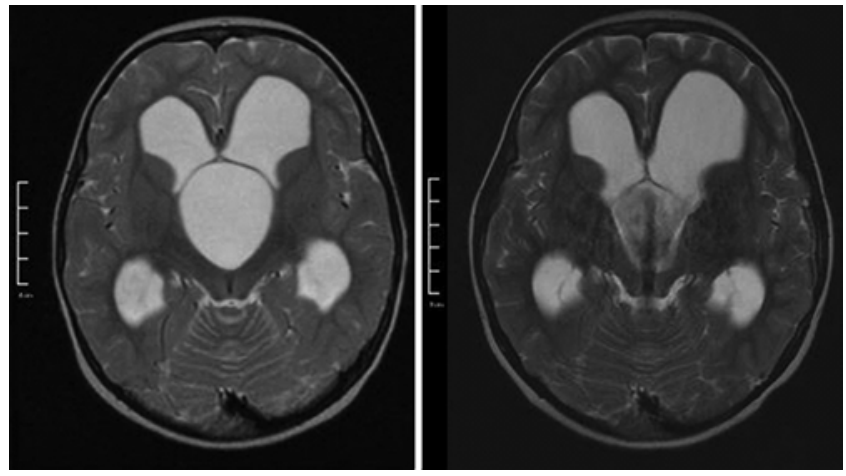

FIG. 1. Case 23. Left: Axial MR image at initial diagnosis (age 2 years) showing a suprasellar arachnoid cyst and associated hydrocephalus, before undergoing endoscopic fenestration. Right: Axial MR image at age 7 , showing a collapsed arachnoid cyst.

45 patients with suprasellar arachnoid cysts, including the surgical outcomes of 37 patients and the natural courses of 8 cases who did not undergo operations. It should be noted that the "unoperated cases" should be considered as "probably" having arachnoid cysts because they could not be pathologically diagnosed. This assumption is based on the radiological impressions from radiologists with expertise in pediatric neuroradiology (professors In One Kim and Jung-Eun Cheon). Hydrocephalus was undoubtedly an absolute indication for surgery, and surgery was effective in terms of the motor developmental delays and head bobbing. However, the decreased visual acuity and endocrine abnormalities were not resolved after surgery. Surprisingly, as the patients grew with stable neurological/ radiological outcomes, endocrine symptoms developed even years after the initial diagnoses. Moreover, new endocrine abnormalities were detected both in the operated and nonoperated patients.

Regarding the surgical indications for suprasellar arachnoid cysts, there is no controversy about hydrocephalus as an absolute indication. ${ }^{9,14}$ The symptoms related to hydrocephalus and increased intracranial pressure appear to resolve after surgery. However, consistent with other previous reports, the endocrine abnormalities ${ }^{2,7,17}$ and long-standing seizures usually did not improve, even after the resolution of hydrocephalus. Similarly, the surgical benefits in cases without hydrocephalus were not clear. Of the 5 patients without hydrocephalus that were operated on, 3 had symptoms unrelated to the cyst (chronic vomiting, nonspecific staring, and strabismus) and underwent operations in the early 1990s when the surgical indications for suprasellar arachnoid cysts were not strictly defined. The other 2 patients had been diagnosed during the fetal period and underwent operations due to enlargement of the cysts during follow-up. An increase in the size of an arachnoid cyst attracts the attention of clinicians, regardless of the location of the lesion, and is a relatively common indication for surgical intervention for an otherwise asymptomatic patient. However, recent reports have questioned the benefits of surgical interventions for asymptomatically enlarged arachnoid cysts and stated that such enlargements almost always stop spontaneously, and the children are neurologically normal. ${ }^{4,12,20}$ It is our cur- 

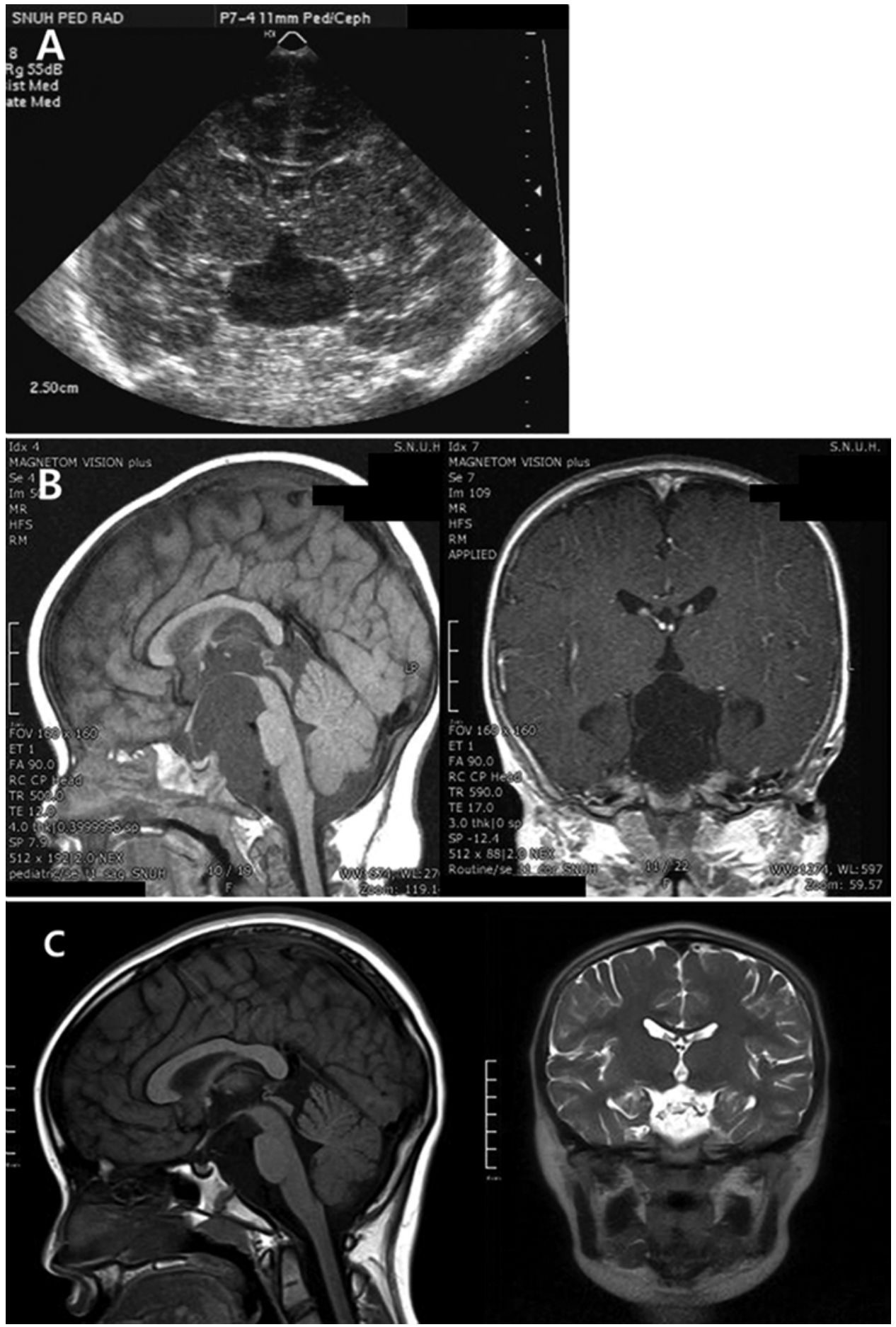

FIG. 2. Case 28. A: Ultrasound image showing a suspected suprasellar arachnoid cyst. B: Sagittal and coronal MR images obtained at 1 year of age, showing a suprasellar cystic lesion with no hydrocephalus. C: Sagittal and coronal MR images taken at 8 years of age, revealing a spontaneously collapsed cyst.

rent policy not to operate on patients with asymptomatic enlargement of a suprasellar arachnoid cyst.

Suprasellar arachnoid cysts are a well-known cause of hypothalamic-pituitary dysfunction. Abnormality in various aspects of this axis has been documented in relation to suprasellar arachnoid cysts. ${ }^{2,18}$ Although endocrine $a b-$ normalities are commonly known to present as symptoms of suprasellar arachnoid cysts, other modes of detection have been mentioned in the literature, e.g., the possibilities of "preexistence" and "posttreatment presentation." 18 Nevertheless, this is the first study to describe in detail the long-term endocrine outcomes of patients with suprasellar arachnoid cysts. Nearly half $(18 / 44,41 \%)$ of the patients suffered from various endocrine symptoms, and some suf- 
fered from these symptoms years after the initial diagnoses of the arachnoid cysts. This phenomenon was observed in both the operated and unoperated groups, including the "posttreated" cases mentioned in another study. ${ }^{18}$ We wondered whether surgical trauma to the neurohypophysis could cause endocrine symptoms during the follow-up period. The development of endocrine disorders during the follow-up evaluations of the unoperated patients $(n=2$ of 8 ), and the patients who were treated with VPS or CPS without fenestration ( $n=2$ of 5), provides direct evidence that endocrine disorders can occur in the absence of surgical trauma. Furthermore, although hydrocephalus alone is known to cause endocrine symptoms, ${ }^{5,15}$ the 2 unoperated patients never experienced hydrocephalus, suggesting that the endocrine symptoms found during the follow-up of patients with suprasellar arachnoid cysts are at least not solely due to the associated hydrocephalus.

One may speculate on the mechanism underlying the endocrine disorders arising later during follow-up based on the complex interplay between both the inhibitory and stimulatory factors that control the hypothalamic-pituitary axis. Normally, the hypothalamic-pituitary-gonadal axis is completely suppressed by the inhibition of hypothalamic GnRH secretion. However, any type of intracranial disturbance, such as hydrocephalus, surgical trauma, or other injury, can interfere with the neurogenic inhibition of hypothalamic GnRH secretion. ${ }^{3}$ Although the exact pathway remains unclear, compressive forces, global or focal ischemia, and impairments of neurotransmitter feedback loops are likely candidates. ${ }^{1}$ Although mechanical compression is usually alleviated by operation, axonal injury may interrupt coordinated transsynaptic and glial-neural communication. Neurogenic inhibition of hypothalamic GnRH secretion physiologically decreases with age. This physiologically lowered threshold for GnRH secretion is prematurely exceeded in those patients with axonal injuries that possibly lead to precocious puberty in childhood. In our study, the 4 patients who already had endocrine disorders at diagnosis were older than those who developed endocrine disorders a few years later. The probability of the development of endocrine disorders possibly increased as the patients became older.

Several suggestions regarding the endocrine management of patients with suprasellar arachnoid cysts arise from the present study. The patients were neurologically and radiologically stable when the endocrine abnormalities were detected, which suggests that routine evaluations by pediatricians are mandatory for patients following successful operations or "asymptomatic" lesions that did not require surgical intervention. Moreover, it should be noted that just as the endocrine symptoms detected as presenting symptoms of suprasellar arachnoid cysts did not improve after surgery, surgery did not appear to prevent the endocrine symptoms that arose during the follow-up period. Furthermore, it may be inferred from such observations that endocrine symptoms may not be suitable as the sole indication for therapeutic or preventive operations for suprasellar arachnoid cysts. Because this study is retrospective in nature, additional studies will elucidate the clinical details of this phenomenon. In fact, routine postoperative evaluation of the endocrine function was not performed for most of the earlier cases and usually the symptomatic cases had been evaluated. Only during the last several years did we routinely check the postoperative hormone levels for the suprasellar arachnoid patients. We hope a detailed protocol for endocrine follow-up that takes into consideration factors such as age of the patients, preoperative endocrine status, and type of management of cysts will be suggested based on our early experiences.

\section{Conclusions}

Suprasellar arachnoid cysts may be detected by various symptoms, and for patients without hydrocephalus, the surgical indication should be carefully chosen. Endocrine symptoms tend to persist after surgery, and new-onset endocrine deficits, such as precocious puberty and GH deficiencies, were detected even years after the initial diagnoses. The fact that considerable numbers of patients with suprasellar arachnoid cysts presented with new endocrine disorders during follow-up heralds the need for routine evaluations of endocrine status.

\section{Acknowledgments}

This research was supported by the Original Technology Research Program for Brain Science through the National Research Foundation of Korea (NRF) funded by the Ministry of Science ICT and Future Planning (grant no. 2015M3C7A1029034). This work was also supported by the Education and Research Encouragement Fund of Seoul National University Hospital (J. Y. Lee).

\section{References}

1. Abdolvahabi RM, Mitchell JA, Diaz FG, McAllister JP II: A brief review of the effects of chronic hydrocephalus on the gonadotropin releasing hormone system: implications for amenorrhea and precocious puberty. Neurol Res 22:123126,2000

2. Adan L, Bussières L, Dinand V, Zerah M, Pierre-Kahn A, Brauner R: Growth, puberty and hypothalamic-pituitary function in children with suprasellar arachnoid cyst. Eur J Pediatr 159:348-355, 2000

3. Al-Holou WN, Terman S, Kilburg C, Garton HJ, Muraszko KM, Maher CO: Prevalence and natural history of arachnoid cysts in adults. J Neurosurg 118:222-231, 2013

4. Al-Holou WN, Yew AY, Boomsaad ZE, Garton HJ, Muraszko KM, Maher CO: Prevalence and natural history of arachnoid cysts in children. J Neurosurg Pediatr 5:578-585, 2010

5. Caporal R, Segrestaa JM, Dorf G: Endocrine expressions of hydrocephalus. A case of primary amenorrhoea revealing a stenosis of the foramen of Magendie. Acta Endocrinol (Copenh) 102:161-166, 1983

6. Cincu R, Agrawal A, Eiras J: Intracranial arachnoid cysts: current concepts and treatment alternatives. Clin Neurol Neurosurg 109:837-843, 2007

7. Crimmins DW, Pierre-Kahn A, Sainte-Rose C, Zerah M: Treatment of suprasellar cysts and patient outcome. J Neurosurg 105 (2 Suppl):107-114, 2006

8. Dagain A, Lepeintre JF, Scarone P, Costache C, Dupuy M, Gaillard S: Endoscopic removal of a suprasellar arachnoid cyst: an anatomical study with special reference to skull base. Surg Radiol Anat 32:389-392, 2010

9. El-Ghandour NM: Endoscopic treatment of suprasellar arachnoid cysts in children. J Neurosurg Pediatr 8:6-14, 2011

10. Gangemi M, Colella G, Magro F, Maiuri F: Suprasellar arachnoid cysts: endoscopy versus microsurgical cyst excision and shunting. Br J Neurosurg 21:276-280, 2007 
11. Hoffman HJ, Hendrick EB, Humphreys RP, Armstrong EA: Investigation and management of suprasellar arachnoid cysts. J Neurosurg 57:597-602, 1982

12. Lee JY, Kim JW, Phi JH, Kim SK, Cho BK, Wang KC: Enlarging arachnoid cyst: a false alarm for infants. Childs Nerv Syst 28:1203-1211, 2012

13. Mattox A, Choi JD, Leith-Gray L, Grant GA, Adamson DC: Guidelines for the management of obstructive hydrocephalus from suprasellar-prepontine arachnoid cysts using endoscopic third ventriculocystocisternostomy. Surg Innov 17:206-216, 2010

14. Miyajima M, Arai H, Okuda O, Hishii M, Nakanishi H, Sato $\mathrm{K}$ : Possible origin of suprasellar arachnoid cysts: neuroimaging and neurosurgical observations in nine cases. J Neurosurg 93:62-67, 2000

15. Morello A, Porcaro S, Lima J, Impallaria P: Endocrine disorder as the only sign of chronic "non-hypertensive" hydrocephalus. J Neurosurg Sci 46:81-84, 2002

16. Ogiwara H, Morota N, Joko M, Hirota K: Endoscopic fenestrations for suprasellar arachnoid cysts. J Neurosurg Pediatr 8:484-488, 2011

17. Starzyk J, Kwiatkowski S, Urbanowicz W, Starzyk B, Harasiewicz M, Kalicka-Kasperczyk A, et al: Suprasellar arachnoidal cyst as a cause of precocious puberty-report of three patients and literature overview. J Pediatr Endocrinol Metab 16:447-455, 2003

18. Trivin C, Couto-Silva AC, Sainte-Rose C, Chemaitilly W, Kalifa C, Doz F, et al: Presentation and evolution of organic central precocious puberty according to the type of CNS lesion. Clin Endocrinol (Oxf) 65:239-245, 2006
19. Yadav YR, Parihar V, Sinha M, Jain N: Endoscopic treatment of the suprasellar arachnoid cyst. Neurol India 58:280-283, 2010

20. Yang SH, Lee KS, Sung JH, Son BC, Jeun SS, Kang JK: Surgical decompression of supratentorial arachnoid cysts in pediatric patients younger than one year. Pediatr Neurosurg 44:465-470, 2008

\section{Disclosures}

The authors report no conflict of interest concerning the materials or methods used in this study or the findings specified in this paper.

\section{Author Contributions}

Conception and design: Wang, Kim. Acquisition of data: JY Lee, YA Lee, Jung. Analysis and interpretation of data: JY Lee, YA Lee, Jung. Drafting the article: JY Lee, YA Lee, Chong, Kim. Critically revising the article: Wang, JY Lee, Chong, Phi. Reviewed submitted version of manuscript: Wang, JY Lee, YA Lee, Jung, Chong, Phi, Shin. Approved the final version of the manuscript on behalf of all authors: Wang. Administrative/technical/material support: Kim, Shin. Study supervision: Shin.

\section{Correspondence}

Kyu-Chang Wang, Division of Pediatric Neurosurgery, Seoul National University Children's Hospital, 101 Daehak-ro, Jongnogu, Seoul 03080, Republic of Korea. email: kcwang@snu.ac.kr. 